\title{
What Goes In, Must Come Out
}

\section{Andrew Hague*}

CellSonic: Manufacturers of Medical Equipment, United Kingdom

*Corresponding author: Andrew Hague, President, CellSonic: Manufacturers of Medical Equipment, United Kingdom, Tel: +1 315210 6307; Email:

\section{Review Article}

Volume 2 Issue 4

Received Date: August 05, 2018

Published Date: August 13, 2018

DOI: $10.23880 /$ eoij-16000173

cellsonic.beauty@gmail.com

\section{Abstract}

The interdependence of all living things affects human health. Food is more than energy alone. There are varieties of minerals that are balanced by the body according to its needs and what it does not need is expelled. If they remain, they cause problems.

Keywords: Health; Illness; Pains

\section{Introduction}

Animals and plants are hosts for bacteria. The sun is the source of all energy that is converted into reproducible life and the forms that the life takes change continuously by mutation. Common to all life is nutrition going in, being absorbed and then something coming out. That absorption is done mostly by bacteria. Let it perform as it prefers and the result is called healthy. Most medical understanding is about what goes in. Equally important is what comes out. If waste does not emerge, there will be illness.

Our health depends on the health of all forms of life around us because the exchange of nutrients and bacteria is all-embracing. No part of the mix can survive in isolation. Feel unwell, consult a doctor and you will most likely be given something to take, something to put into your body. There will be an assumption that either something breeding inside you needs to be killed or that the nutrients necessary for sustaining your energy are inadequate. Seldom is the output mechanism questioned.

\section{Bladder}

The bowel and bladder are two of the main emitting organs. With a healthy diet and exercise constipation should never occur [1]. Elimination of urine is evidence of the kidneys working. Note that they are not the only exit route. By perspiration, the skin releases a lot of liquid and it is seldom realized how essential it is to sweat. Sweat a lot leaving nothing for the kidneys and the result can be dire. Without flushing, the kidneys accumulate particles which can solidify to stone and grow in size.

The northern and southern flanks of the Mediterranean Sea and further into the Middle East are described by urologists as The Stone Belt. This is where kidney stones frequently form. People sweat a lot, do not drink enough and the kidneys are not irrigated. Suffers claim that kidney stones inflict the worst of all types of pain.

Removing kidney stones used to be a major surgical operation and patients would avoid surgery and suffer the pain until large deposits called stag horn stones formed and surgery was unavoidable. Thankfully, lithotripters were developed to break the stones into tiny particles that would flush out with the urine [2]. The history of the development of lithotripters is one of the most important accounts in the evolution of medicine because it leads to the healing of diabetic ulcers rendering amputation unnecessary and eventually to discovering how to stop cancer cells replicating further mutant cells $[3,4]$. 


\section{Kidney Failure}

The importance of the kidney is evident for we have two. Would it help if we had more than one heart? Dialysis three times a week occupies three days and still leaves the patient encumbered. Here are the results of measurements on a patient with kidney failure treated with a CellSonic VIPP (very intense pressure pulse) machine by Professor Ramesh Chouhan.

\begin{tabular}{|c|c|c|c|c|c|c|}
\hline NAME: anon & AGE: 72 YRS & \multicolumn{5}{|c|}{ FEMALE } \\
\hline Date & & \begin{tabular}{|c|} 
05-Aug- \\
17
\end{tabular} & \begin{tabular}{|c|} 
18-Aug- \\
17
\end{tabular} & 26-Aug-17 & 17-Sep-17 & 17-0ct-17 \\
\hline & $\begin{array}{l}\text { Normal } \\
\text { Range }\end{array}$ & \multicolumn{3}{|c|}{ Weekly 3 times dialysis } & \multicolumn{2}{|c|}{ Weekly 2 times dialysis } \\
\hline Creatinine, Serum & $.55-1.02$ & 4.67 & 3.89 & 5.51 & 6.27 & 5.7 \\
\hline Blood Urea & $15-40$ & 36 & 31 & 53 & 74 & 57 \\
\hline Sodium, Serum & $136-145$ & 139 & 143 & 139 & 139 & 137 \\
\hline Potassium, serum & $3.5-5.1$ & 3.8 & 3.7 & 4.5 & 4 & 3.5 \\
\hline Chloride, Serum & 98-107 & 100 & 97 & 102 & 101 & 102 \\
\hline $\begin{array}{c}\text { Dry Weight gain between dialysis per day } \\
\text { (Grams) }\end{array}$ & 1 kg per day & 700 gms & $600 \mathrm{gms}$ & 500 gms & 400 gms & $400 \mathrm{gms}$ \\
\hline Ultrasound R-Kidney & & $6.8 \times 3.1$ & & $6.8 \times 3.1$ & & \\
\hline Ultrasound L-Kidney & & $7.0 \times 3.1$ & & $7.0 \times 3.2$ & & \\
\hline MDRD GFR & & & & & 8 & 8 \\
\hline Creatinine, Serum & $.55-1.02$ & & & & 6.27 & 6.27 \\
\hline Creatinine, Urine & $25-400$ & & & & 34.65 & 34.65 \\
\hline Creatinine Clearance Test & $80-120$ & & & & & \\
\hline Total liquid intake per day & 1 ltr & 1 ltr & 1 ltr & $1 \mathrm{ltr}$ & 1.25 Ltrs & 1.25 Ltrs \\
\hline Post Dialysis day Urine output & Negligible & $\begin{array}{c}\text { Negligibl } \\
\mathrm{e}\end{array}$ & $\begin{array}{c}\begin{array}{c}\text { After } 8 \\
\text { hrs }\end{array} \\
\end{array}$ & $\begin{array}{c}5 \text { hrs } \\
\text { onwards }\end{array}$ & $\begin{array}{c}3 \text { hrs } \\
\text { onwards }\end{array}$ & $\begin{array}{c}3 \text { hrs } \\
\text { onwards }\end{array}$ \\
\hline Total volume of Urine & & & & & $>750 \mathrm{ml}$ & $>900 \mathrm{ml}$ \\
\hline
\end{tabular}

\begin{tabular}{|l|}
\hline Physical improvements \\
\hline increase of urine output \\
\hline improved appetite \\
\hline dry skin tone turning to normal \\
\hline reduced skin irritation \\
\hline less gain of dry weight \\
\hline reduced leg swelling \\
\hline Overall improvement in health \& relief from depression, anxiety \& other problems \\
\hline
\end{tabular}

Table 1: Results of Measurements on a Patient with Kidney Failure Treated with a CellSonic VIPP.

I was introduced to the patient at Professor Chouhan's clinic. She was with her son who spoke English and he confirmed that his mother looked forward to the CellSonic treatments because they always left her feeling much better and she was now seeing that they would restore her kidneys to normal. More patients have been added to the CellSonic kidney treatment programme and good progress is reported for all of them. It is not an instant cure because new tissues take time to grow and have to be stimulated to grow. It is interesting that no drug can cause these changes. Only the effect of the VIPP (very intense pressure pulse) technology works. Quite apart from the benefit to the patient, the cost and time savings are enormous. Here we see a treatment in progress with CellSonic VIPP. 


\section{Ergonomics International Journal}

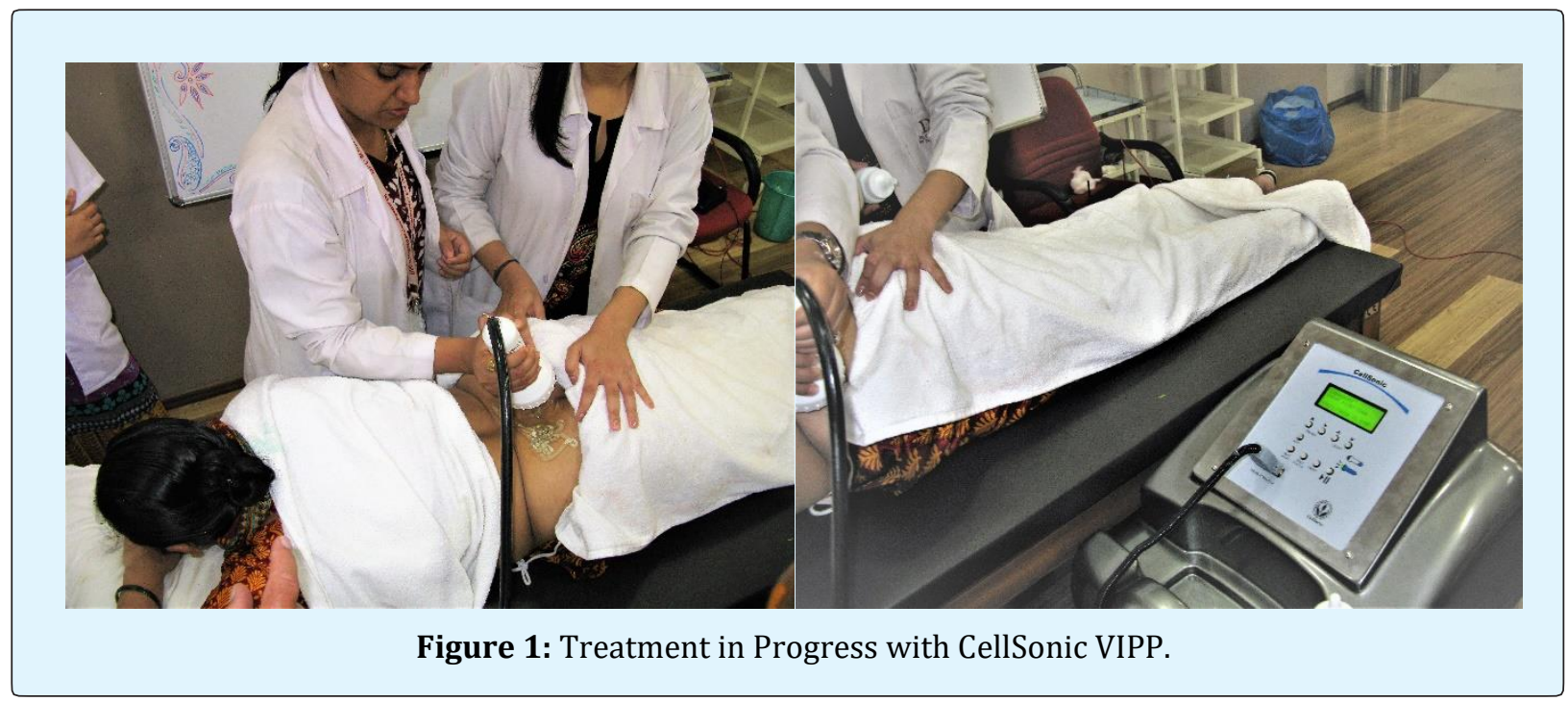

\section{Flexible Plumbing}

If the skeleton is the chassis, the organs and tubes are the plumbing. There has to be constant flow through the pipes. Blood must circulate carrying oxygen and platelets to all parts of the body. If blood is not present, tissues die. To maintain flow, the body must move. Exercise is a term we have started to use in recent years since it became possible to sit and lie for hour after hour. We now know that we must move to keep the contents of the flexible pipes travelling along. Think of the body as a factory in which raw materials come in to be processed into energy with unwanted side products ejected. Without the body moving, only the heart is beating and that too slows down until it is unable to push anymore. Idleness kills.

I remember almost fifty years ago, a friend in the cycling club, remarking that the colour of urine on a Monday was darker than later in the week. We were cycling up to a hundred miles at the weekends. That exercise flushed from our bodies' rubbish that showed in the urine as dark brown. During the week, riding fewer miles, the elimination process was less vigorous and the urine became almost colorless. Not scientific measurement, of course, but evidence nevertheless and I believe that friend went on to a distinguished academic career in science. Note that all investigations begin with a simple observation. It was later realized when on a long cycle tour lasting more than two weeks that the urine colour remained almost colorless. The conclusion was that all the impurities were being flushed through continuously with regular exercise and by drinking more water than usual.

\section{Sweat}

A further observation when cycling in the heat is that the skin is dry. Don't let that fool you into thinking you are not sweating. Come to a stop and within a minute you are covered in sweat. Whilst riding with air blowing over you, the sweat is dried as soon as it emerges. Only when you stop and lose the cooling effect of the draught do you realize the amount of water being lost. This volume is not available to the kidneys and has to be replenished to avoid dehydration.

Interestingly, the sit-up posture on a bicycle is more efficient than the recumbent, lying down, position because the body acts as an air-cooled engine [5]. Overheating reduces efficiency. Although the upright rider creates more wind resistance, the air draught aids cooling. A streamlined cocoon that makes the recumbent bicycle look like a torpedo is only efficient over short distances during which high speeds can be attained and then the rider emerges lathered in sweat.

When exercising, an average person can sweat 1.4 litres an hour [6]. This is mostly water because the prime function of sweat is cooling by evaporation. With the water comes sodium plus minerals, lactic acid and urea, potassium, calcium and magnesium. Some trace elements are also found of zinc, copper, iron, chromium, nickel and lead. The significance of sweating can best be understood by thinking of the consequences of not sweating; all those chemicals and minerals would remain and accumulate in the body. Without sweating, would they filter out through the bladder and bowel? It is doubtful because we see in 


\section{Ergonomics International Journal}

the body an operating system to maintain health dependant on exercise without which health fails. Sweating is therefore as necessary as all the other bodily functions. Unfortunately, there was a social attitude that deplored women sweating [7]. Gone are those attitudes of previous years when skirts had to be long enough to hide an ankle and waists squeezed so tight that the stomach failed.

\section{Alcohol}

The chemical name for alcohol is ethanol $(\mathrm{CH} 3 \mathrm{CH} 2$ $\mathrm{OH}$ ). Medically, it is a poison. Socially, it is a lubricant. That people like to detach their minds is observable everywhere. Governments cannot ban it and have tried. Some religions succeed in banning it and others support it. The medical consequences of imbibing ethanol are serious. This is not just something that goes in and will flow out. When it is in, metabolic changes are made before the residues come out.

A paper by Laura A. Stokowski, RN, MS entitled "No Amount of Alcohol Is Safe" should be compulsory reading for anyone over the age of twelve [8]. An earlier report from 2007 by the United States Department of Health and Human Services, Alcohol Alert, is not sanctimonious and the warning is clear [9]. Chemicals called enzymes help to break apart the ethanol molecule into other compounds (or metabolites), which can be processed more easily by the body. Some of these intermediate metabolites can have harmful effects on the body. Most of the ethanol in the body is broken down in the liver by an enzyme called alcohol dehydrogenase (ADH), which transforms ethanol into a toxic compound called acetaldehyde (CH3CHO), a known carcinogen. However, acetaldehyde is generally short-lived; it is quickly broken down to a less toxic compound called acetate ( $\mathrm{CH} 3 \mathrm{COO}-$ ) by another enzyme called aldehyde dehydrogenase (ALDH). Acetate then is broken down to carbon dioxide and water, mainly in tissues other than the liver.

Although acetaldehyde is short lived, usually existing in the body only for a brief time before it is further broken down into acetate, it has the potential to cause significant damage. This is particularly evident in the liver, where the metabolism takes place. Some alcohol metabolism also occurs in other tissues, including the pancreas and the brain, causing damage to cells and tissues. Additionally, small amounts of alcohol are metabolized to acetaldehyde in the gastrointestinal tract, exposing these tissues to acetaldehyde's damaging effects.
You should read the Alcohol Alert paper and if it leaves you in need of a drink, be sure it is spring water. The notion that alcohol can flush out of the body is nonsense. Like all poisons, it does damage. It may be possible to repair that damage over time and abstinence. The frustration, medically, is that the patient voluntarily swallowed the poison and usually paid a lot of money for it. This desire to detach the brain and ignore the consequences is a feature unique to humans. Our brain distinguishes us from other animals, is supposed to be clever and yet fails in many cases to protect the individual. We cannot help those who do not want to be helped.

In addition to alcohol which has been distilled from ancient times even before agriculture, humans also like ingesting anything else that leaves them disoriented or worse. Magic mushrooms are celebrated. Narcotics are big business. Their addictive quality strengthens demand to the level of prioritising its consumption above all else, even to accepting a longer stay in prison (which confirms that for this problem prison is useless).

There appear to be more people eager to endanger their health than to preserve it. Cancer and diabetes are not infectious diseases and are now seen as avoidable. As Laura Stokowski points out, the role alcohol plays in preventing the immune system from intercepting and destroying mutant cells is denied when the patient is asked about their drinking habits. Prosperity allows many families to have wine with every meal. Do they think it is healthy and full of vitamin $\mathrm{C}$ from grapes?

Since I developed the means of stopping cancer more than two years ago, I have become acquainted with nutritional cures for cancer which have the merit of supporting the immune system and thereby killing incipient cancer cells. In all cases, the nutrients and food supplements contain minerals and vitamins which do not store in the body and if they did they may become as much a danger as the problem they are trying to solve. For the cure to work, what goes in, must come out. This means that all exits have to be open, not just the bowel and bladder.

Eyes wash with water when we blink, saliva glands wet the mouth, the nose runs and wax forms in the ears. As well as oiling the skin to protect against constant water and at other times the baking of the sun, our pores release chemicals that should come out after they have fulfilled their role in maintaining balances. 


\section{The Microbiome Balance}

One way to understand the balance is to think not just of the balance of the body's nutrition but the requirements of our microbiome, the masses of bacteria that collectively support our health. It can be argued that the microbiome is not there to support us but that we are living to host the microbiome. There is a constant balancing programme running to keep the bacteria fed so that it can reproduce without harming its host. The behaviour of gut bacteria is controlled through the vagus nerve, the 10th cranial nerve that runs from the brain stem down to the abdomen [10]. Dr Mercola reports that the makeup of gut microbiome can have a tremendous influence over psychological health and wellbeing affecting both the general mood and a risk of more serious mental health dysfunction.

\section{The Bowel}

The black, hard pieces of gravel in the tube in this photo were for many years in the bowel of a patient who was being treated for cancer. Thankfully, the doctor took a holistic approach and by a thorough examination found what had been causing pain. That was a problem; some of the pain was from cancer and some was from other failings such as this bowel detritus. That the immune system had been unable to support the patient is obvious. The doctor succeeded in returning the health to where it had been twenty years earlier and hoped that the patient had learned what to do to stay healthy.

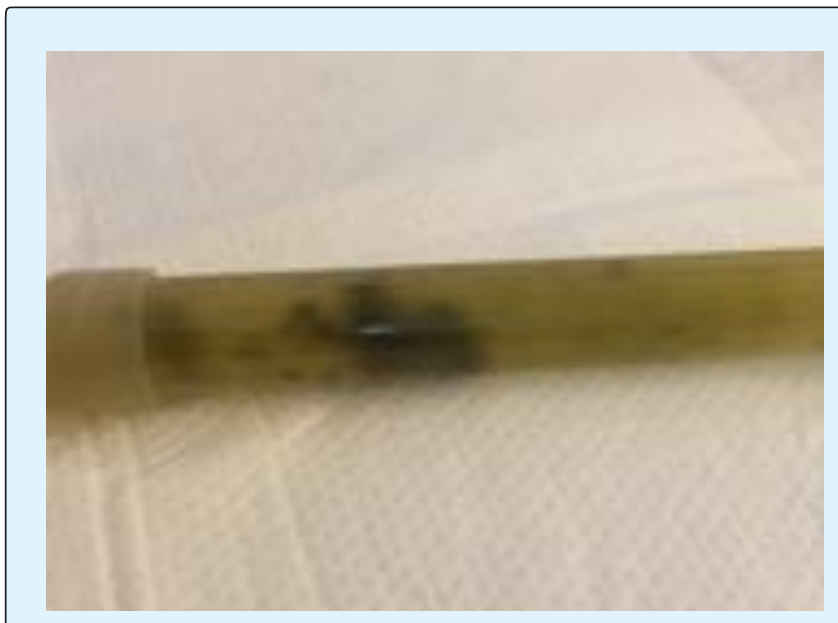

Figure 2: The black, hard pieces of gravel in the tube.

\section{Opening the Valves}

It may seem unnecessary to advise a man how to urinate but what is obvious to a child is more difficult as he ages. The ladies have problems of a different kind. As the urology student soon learns, the old men have difficulty opening the valve whilst the ladies may have trouble keeping it closed. The main difference is that the female urethra is short and the male urethra more than four times longer. The source of this cross-section diagram is unknown. It was found on the internet.

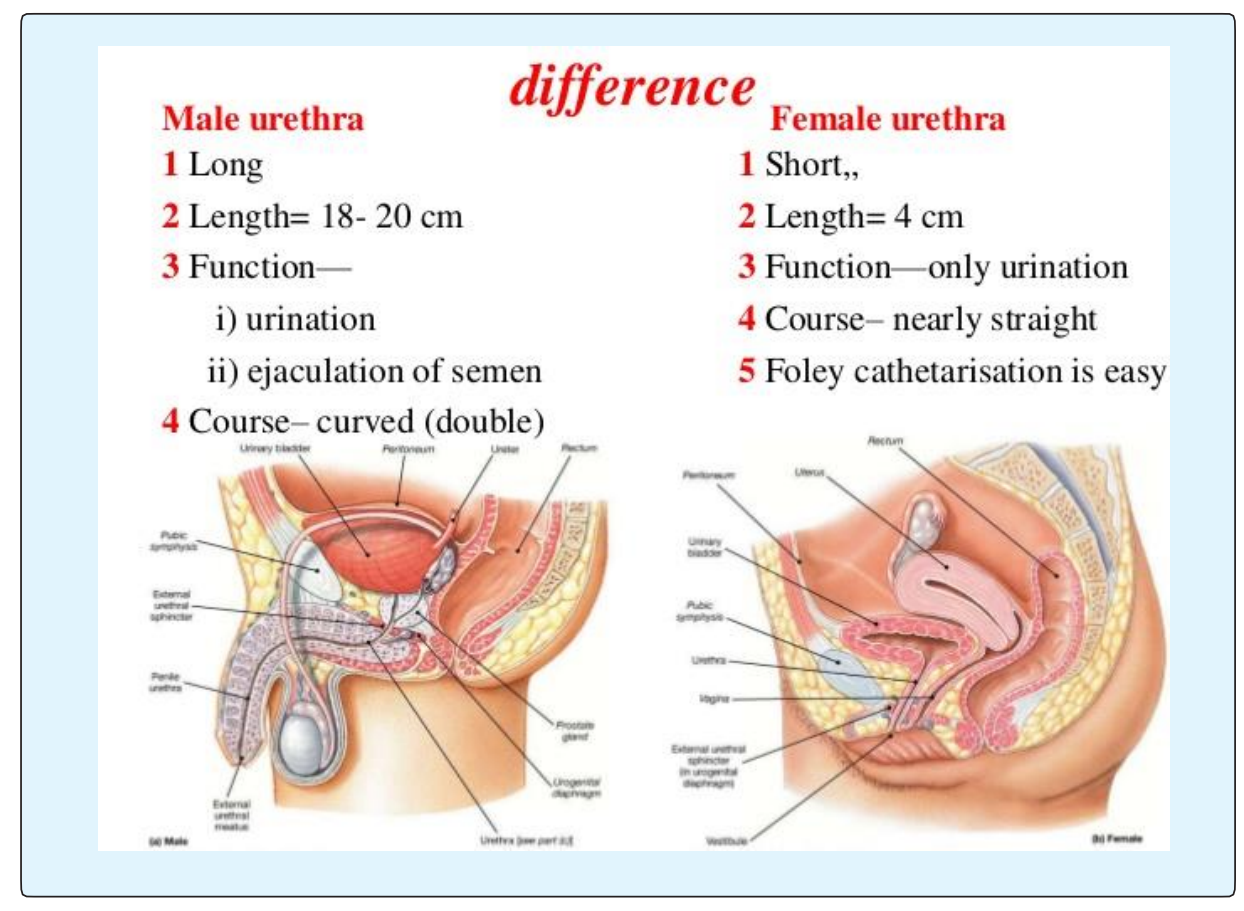




\section{Ergonomics International Journal}

There is a lot of publicity advising men to have their prostate checked if they are frequently needing to urinate. If the prostate gland compresses the urethra, the flow of urine is restricted. The frequency of urination and the amount passed is measured with a uroflow meter [11]. The importance of the prostate inspection is to check if a cancer growth is causing the obstruction.

A problem seldom admitted by the elderly is reduced elasticity. This can be see easily in wrinkled skin. It is also happening internally. A young bladder would fill and then empty powerfully squeezing the contents. As the elasticity of the bladder deteriorates, it lacks the pressure to expel the urine. It could be this, not just an expanding prostate gland that is the problem.

As you get older, you learn where the toilets are. When you go to a new place, identify the toilets in readiness and the rule is never missing an opportunity to use the toilet because you don't know when you will find the next one. When you urinate and think the bladder has emptied, wait, maybe thirty seconds, and then a few more drops will come out. That delay has given the bladder time to shrink. Removing the last few dregs is important because if they are left inside they can cause infection leading to further problems. The usual cure is to drink an excessive amount of water and flush out the infection.

The body protects itself from dehydration. When it senses aridity from dry air which can be the weather or air conditioning, it will retain water. The stomach can be bloated. Ankles and wrists swell. Move to a cooler, humid environment and quickly the bladder will be back in action.

Opening the bowel is assumed to be a matter of squeezing. That is sometimes easier said than done. Toilet seats are a recent invention in the evolution of humans and always too high. The natural posture for defecating is to squat. This positions the bowel and anus ideally to release the contents.

\section{Food and Soil}

Food intake is fundamental. If the food lacks nutrients, the body suffers. The nutrients come from soil either into plants eaten directly or by the plants to animals that are eaten. Either way, soil quality is essential for human health.

The industrialisation of agriculture has leached soils. Yields are sustained by fertiliser that does not lead to better nutrition. Crops are sold by weight, not by nutritional quality. Fifty years ago, the strong man, cartoon character, Popeye ate spinach for strength. Now he would need to consume fifty times more spinach to ingest the same amount of iron that he got fifty years ago. The crops may look and weigh the same but what is needed in them is not there.

Just as the pharmaceutical industry has replaced natural foods with synthetic additives so too has the fertiliser industry ignored the benefits of natural methods of recycling bacteria back into the soil [12,12a,13]. An interesting company is CBX based in Arizona in the USA and known in Europe as Environment Green based in Norway. CBX discovered Leonardite, an ancient geological deposit of plant material that has not turned to coal and decomposed slowly over millions of years until only the mineral elements remain. Their websites show with and without photos of crops treated with and without CBX and the differences are startling [12a]. Follow the link to what CBX call the $5^{\text {th }}$ element. There is life in soil.

\section{$>\quad$ Soil}

In 1 teaspoon of soil there can be the following numbers of microbes:

- 1 to 600 million individual bacteria

- 5 to 60,000 yards of Fungal Hyphae

- 100 to 100,000 Protozoa

- 5 to 500 beneficial nematodes

- Few to several hundred thousand Microarthropods

These organisms help convert organic matter and soil minerals into the vitamins, hormones, diseasesuppressing compounds and nutrients that plants need to grow.

Healthy soil makes healthy plants and promotes the health of those who eat the plants. The concept of what goes in, must come out is displayed in the soil enrichment company called Bat Master [14]. They have found an inexhaustible supply of bat guano (dung) in deep caves that rebalances and replenishes exhausted soils so successfully that it rids plants of disease better than any pesticide. They call their product a plant food. Apparently, there would be legal complications if it were called fertiliser.

Bats eat insects. Ingesting the variety of foods from many types of insects delivers to the bat's faces a bountiful range of minerals and decayed bacteria. This is what Popeye needs at the start of his food chain. 


\section{Ergonomics International Journal}

\section{Conclusion}

We are scared. We do not know where the food and drink we put into ourselves comes from. We have to trust the suppliers because we have no choice. Even farmers buy food in the shops. In this modern world, hardly anyone grows everything they need for every day of the year. The best we can do is being careful and hope that what goes in will come out without doing harm whilst inside us.

\section{References}

1. Andrew Hague (2018) The Exercise Continuum and the Role of Doctors. OAJ Gerontol \& Geriatric Med 3(5): 555622.

2. Lithosplit 4.1 Digital Intra Corporeal Pneumatic Lithotripsy.

3. http://www.cellsonic-medical.com/wound.htm

4. Andrew Hague (2017) Review of reports of curing cancer with CellSonic VIPP machines. Gen Med Open.
5. (1974) How bicyclists keep cool. Bicycling Science by Whitt and Wilson. MIT Press, pp. 1-57.

6. https://en.wikipedia.org/wiki/Perspiration

7. Andrew Hague (2017) The Body's Operating System. ARC Journal of Research in Sports Medicine 2(2): 1619.

8. (2014) No Amount of Alcohol Is Safe. Medscape.

9. Alcohol Alert.

10. Mercola (2018) Gut Microbiome May Be a GameChanger for Cancer Prevention and Treatment.

11. dyna \& digiFLOW

12. http://cbxproducts.com/2_WHATisCBX.html

13. 12a.http://cbxproducts.com/2_2the5thElement.html

14. https://www.enviromgreen.com/

15. https://www.batmaster.co.uk/ 